\title{
A inserção e a atuação profissional do psicólogo no campo das políticas sociais no Rio Grande do Norte
}

\author{
The professional insertion and practice of the psychologist in the field of social policies in the \\ state of Rio Grande do Norte
}

Pablo de Sousa Seixas ${ }^{[0]}$, Oswaldo Hajime Yamamoto ${ }^{[b]}$

\footnotetext{
${ }^{[a]}$ Doutorando em Psicologia da Universidade Federal do Rio Grande do Norte (UFRN), Natal, RN - Brasil, e-mail: pablo.seixas@gmail.com

${ }^{[b]}$ Doutor em Educação pela Universidade de São Paulo (USP), professor titular da Universidade Federal do Rio Grande do Norte (UFRN), Natal, RN - Brasil, e-mail: oswaldo. yamamoto@gmail.com
}

Recebido: 16/12/2010 Received: 12/16/2010

Aprovado: 14/04/2011 Approved: 04/12/2011

\section{Resumo}

O objetivo do presente estudo foi investigar a inserção e a atuação profissional do psicólogo no campo das políticas sociais no Rio Grande do Norte. Um questionário composto de quatro partes (dados gerais, formação acadêmica, formação complementar e exercício profissional) foi aplicado em 294 psicólogos inscritos no CRP-17. Os resultados mostram uma inserção significativa do psicólogo no campo das políticas sociais (41\%). As características sociodemográficas dos psicólogos não diferem das apresentadas pela literatura: mulheres, jovens, advindas de família com faixa renda de sete a 15 salários mínimos. A maior parte é graduada em instituições públicas e faz especialização na área clínica. Os profissionais estudados aparentam estar em piores condições de trabalho, se comparado com o resto da categoria. Os psicólogos que atuam em instituições de Assistência Social são aqueles que apresentam o maior grau de precarização no trabalho. As atividades desenvolvidas não apresentam novidade, com consolidação de práticas conservadoras ao invés de inovações efetivas, corroborando o questionamento à profissão de não contemplar demandas apresentadas ao profissional de Psicologia no campo das políticas sociais. Com este cenário de reprodução de valores liberais, confirmam-se os padrões clássicos de atuação e difunde-se uma prática apolítica e acrítica. Reitera-se a importância de estudos críticos, que organize metas para a categoria, com intuito de transformações políticas que contemplem o cenário atual.

Palavras-chave: Psicologia. Exercício profissional. Política social.

\section{Abstract}

The purpose of this study was to investigate the professional insertion and practice of psychologists in the field of social policies in the State of Rio Grande do Norte, Brazil. A questionnaire consisting of four parts (general data, academic education, additional education and professional experience) was applied to 294 psychologists enrolled with CRP-17 (Regional Psychology Counsel). The results show a significant insertion of psychologists in the field of social policies (41\%). The socio-demographic characteristics of psychologists do not differ from those presented in the literature: young women, from families with income ranging from 7 to 15 minimum wages. The majority has an undergraduate degree from public institutions and is specializing in the 
clinical area. The professionals studied appear to be in worse working conditions compared to the rest of the category. Psychologists who work in Social Care institutions show a larger degree of precariousness at work. The activities developed do not present any novelty, with consolidation of conservative practices rather than effectively making innovations, thus corroborating the questioning about the profession not contemplating demands presented to the psychology professional in the field of social policies. Having this scenario in hand which reproduces liberal values, classical patterns of activity are confirmed and an apolitical and non-critical practice is spread. It reiterates the importance of critical studies, which organize objectives for the category, aiming at political changes to contemplate the current scenario.

Keywords: Psychology. Professional practice. Social policy.

\section{Introducão}

O campo profissional da Psicologia passou por várias configurações ao longo dos anos. Um dos aspectos mais relevantes diz respeito à substituição gradual e progressiva do trabalho autônomo, que marcou a profissão desde a sua regulamentação, pelo trabalho assalariado (Bastos, 1990; CFP, 2004; Macedo, Heloani \& Cassiolato, 2010). De fato, desde meados da década de 1980 , podemos perceber que o caráter assalariado vem caracterizando a profissão, a despeito de a Psicologia continuar carregando uma imagem liberal, possivelmente associada ao modelo clínico-médico hegemônico (Bastos, 1988; CFP, 2001; Mello, 1975; Yamamoto, 2007).

Dentre os principais empregadores da Psicologia encontra-se o Estado. 0 setor público vem, ao longo das décadas, empregando um contingente cada vez maior de profissionais. Essa ampliação de quadros que ocorreu nas políticas sociais nas últimas duas décadas (notadamente a partir do final da década de 1980, marco da redemocratização brasileira) acaba por incluir categorias ocupacionais antes ausentes no setor, possibilitando então ao psicólogo o ingresso no rol de profissões responsáveis por um conjunto de políticas sociais no Brasil (Campos, 1983; Dimenstein, 1998; Yamamoto \& Oliveira, 2010).

A entrada dos psicólogos no campo das políticas sociais tem sido debatida por diversos autores, e sua discussão abrange desde reflexão sobre a formação dos psicólogos até a defesa pelas entidades de um projeto político para a categoria. A essa discussão da inserção no campo das políticas sociais, Yamamoto $(2003,2007)$ reforça a importância da ampliação do setor como fruto das discussões políticas no momento da redemocratização brasileira, e dos embates teórico-políticos feito pelas entidades a partir da denúncia do caráter elitista da profissão. Desde a década de 1970, Mello (1975) já apontava esse caráter elitista, crítica essa que foi seguida por diversos outros pensadores e pesquisadores da área (Botomé, 1979; Campos, 1983, 1990; Figueiredo, 1989; Yamamoto, 1987). No entanto, mesmo com um aumento significativo do discurso do compromisso social e as tentativas de parte da academia e das entidades de estruturarem um projeto político, essa orientação não é hegemônica para a categoria, e (acredita-se) não é forte o suficiente para ter movimentado a profissão em direção às políticas sociais. Acredita-se, então, que, na presente situação, nas mudanças políticas que o Brasil tem passado desde o período da abertura democrática e o impacto econômico de orientações neoliberais para o Estado brasileiro, forçaram a entrada dos profissionais no campo das políticas sociais. Sem recair na tentativa de explicações "monocausais", a entrada maciça dos psicólogos no setor do bem-estar, nesse momento, parece estar mais associada a uma expansão das oportunidades profissionais, propiciados pela política de proteção social do atual governo, do que por um movimento "interno", seja político, seja teórico-epistemológico da profissão. Ou seja, os psicólogos brasileiros passam a acatar esse "chamado", não só em função do aumento e entrada nas discussões classicamente chamadas de "compromisso social" (Bock, 1999; Lopes, 2005; Silva, 2004), mas, sobretudo, pelas mudanças no mercado de trabalho. Com a crise nos anos 1990, diminuição do poder de compra da classe média, e retração de mercado de trabalho, o psicólogo migra para o campo das políticas sociais como um escape da crise financeira que o assola.

Essa constatação tem sido feita a partir da análise da conformação da categoria ao longo dos anos, pelos 
estudos chamados classicamente de "mapeamentos profissionais", presentes enquanto produção teórica desde o início da regulamentação do psicólogo, em 1962.

A partir dessa entrada no campo das políticas sociais, não só houve alterações nas condições, mas uma perspectiva mesmo de mudanças na atuação, em função da expectativa gerada pela entrada nesse novo campo. Essa entrada maciça não foi acompanhada de estudos que permitissem compreender a conformação do campo no Brasil e suas inter-relações.

A fim de investigar melhor a relação entre o psicólogo e o campo das políticas, foi realizada uma pesquisa na cidade de Natal, RN para levantar a quantidade de profissionais que trabalham nesse novo campo, suas condições de trabalho e suas características de atuação profissional. Este artigo objetiva apresentar os dados coletados na pesquisa, bem como avaliar o impacto as informações para a categoria, nas instâncias de representação profissional e entre as entidades que pensam a formação de psicólogo.

\section{Método}

Esta pesquisa caracteriza-se como descritiva, de caráter exploratório. Um questionário composto por quatro partes, compreendendo dados gerais, a formação acadêmica, a formação complementar (acadêmica e profissional) e o exercício profissional (inserção e atuação profissional), foi elaborado para as finalidades deste estudo.

A pesquisa, de caráter censitário, visou a atingir todos os psicólogos residentes e adimplentes com o sistema conselho (aptos legalmente a exercer a profissão) no Estado do Rio Grande do Norte, RN. Para tanto, o questionário foi aplicado no dia da eleição para a recomposição da direção do Conselho Regional de Psicologia, 17ª . Região e do Conselho Federal de Psicologia, tendo em vista o caráter obrigatório do voto para quem é inscrito no Sistema Conselhos ${ }^{1}$.

Com esse procedimento, foi obtida uma amostra acidental de 294 profissionais do total de 800 psicólogos inscritos no CRP-17 na época da pesquisa ${ }^{2}$.
Por se tratar de uma pesquisa exploratória, foi realizada uma análise preliminar nos questionários aplicados, no qual foram selecionados 121 psicólogos que trabalham com políticas sociais no $\mathrm{RN}^{3}$. Em seguida, os dados foram inseridos no programa Statistical Package for the Social Sciences (SPSS) for Windows ver. 15 e foram submetidos à análise.

\section{0 psicólogo no campo das políticas sociais}

\section{Inserção no campo das políticas sociais}

Um dos dados mais importantes obtidos nessa pesquisa, diz respeito à quantidade de profissionais que trabalham com política social no Rio Grande do Norte. Do total de questionários analisados (294), obteve-se um número de 121 psicólogos, que representa aproximadamente $41 \%$ do total (Figura 1):

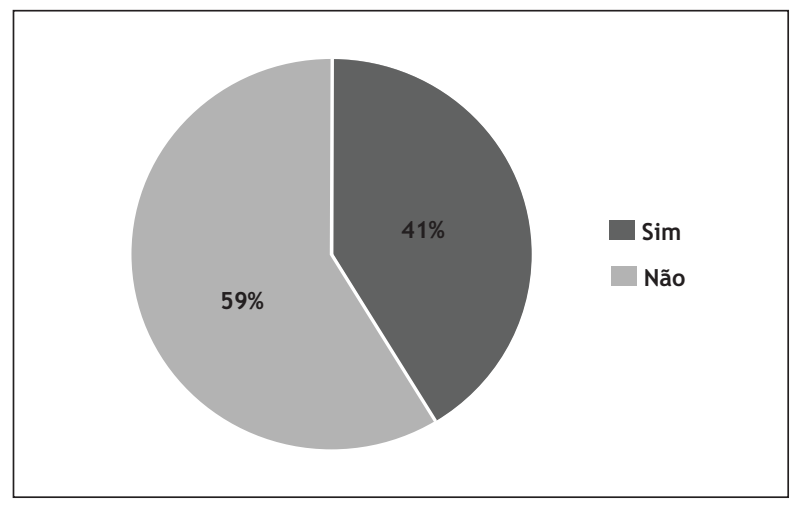

Figura 1 - Porcentagem de psicólogos que trabalham com políticas sociais Fonte: Dados da pesquisa.

A vinculação de $41 \%$ dos profissionais no campo das políticas sociais, em que pese à expectativa expressa na introdução de que o psicólogo vinha gradativamente se inserindo nesse campo não deixa de ser surpreendente. Esse dado retrata uma nova configuração para a Psicologia brasileira, fato que não deve passar despercebido pelas entidades representativas da categoria. Entender

1 Aos psicólogos que não quiseram, ou não puderam, responder ao instrumento no momento da votação foi sugerida a opção de envio por forma eletrônica (e-mail) ou envio pelo correio, recebendo, neste último caso, envelope selado com o GPM\&E como destinatário.

2 Informação fornecida pelo CRP-17 no dia 27 de agosto de 2007.

${ }^{3}$ Como critério de seleção, foram analisados os locais de trabalho desses profissionais, tendo como aspecto principal se a finalidade fundamental da instituição envolvia, ou não, a gestão ou a execução de políticas sociais. 
que quase a metade dos profissionais está inserida no campo das políticas sociais muda não só a imagem da profissão nos meios externos (mercado de trabalho), mas conclama a uma discussão de seu papel na sociedade e uma reorientação das instituições formadoras.

\section{Caracterização geral}

Na caracterização geral dos estudados, não encontramos nenhuma grande discrepância com relação aos dados já registrados na literatura (Bastos, Gondim \& Rodrigues, 2010; Rosas, Rosas \& Xavier, 1988). Ou seja, uma presença maciça de mulheres, jovens (57,9\% abaixo de 40 anos), e oriundos da chamada "classe média" brasileira, cujas famílias ganham entre 7-15 salários mínimos (SM). Importante ressaltar que é a renda familiar, e não a renda singular do psicólogo.

Quanto à formação acadêmica, os psicólogos da amostra são formados primordialmente nas Instituições de Ensino Superior - IES - públicas, particularidade que difere da situação nacional. No RN, por muito tempo, a única instituição formadora do estado foi a Universidade Federal do Rio Grande do Norte (UFRN), responsável por 70\% dos egressos. No Brasil, as instituições públicas são responsáveis por apenas $20 \%$ dos egressos, o que confere uma particularidade a situação da Psicologia no RN. A tendência nos próximos anos, no entanto, é observar uma inversão desse quadro, uma vez que já existem três IES privadas com o curso de Psicologia, todas com uma quantidade igual ou superior de alunos se comparado com a UFRN.

Esses profissionais são formados recentemente, e escolheram como campo de estágio obrigatório, à época da graduação, a área clínica. Mesmo considerando historicamente a baixa oferta de outros campos de estágio e a tentativa da área clínica de ampliar suas concepções teórico-práticas, essa ainda é uma questão preocupante. Sobretudo, se considerarmos o estágio curricular como uma oportunidade privilegiada para a preparação para o trabalho, é questionável se o modelo clínico poderia fornecer a base adequada e suficiente, do ponto de vista dos seus procedimentos e de seu aporte teórico-metodológico, para o profissional atuar com políticas sociais.

Outro dado importante refere-se à formação complementar: 77,2\% dos psicólogos procuram alguma formação complementar, seja especialização (63\%), mestrado (11\%) ou doutorado (2,5\%). A questão da formação continuada é relevante, sobretudo quando se trata de temas recentes, como o da política social. Por isso, pesquisamos em qual área situa-se essa formação complementar, e percebemos que a área mais procurada é a da clínica. Fazemos a ressalva que, no RN, ainda não existem muitos cursos de pós-graduação no campo das políticas sociais, mas ainda permanece o impacto de nesse campo os profissionais ainda optarem por, mesmo trabalhando com políticas sociais, ter sua formação complementar em um campo tradicional.

\section{A inserção profissional do psicólogo no campo das políticas sociais}

A maneira pela qual um psicólogo se insere em seu campo profissional espelha um funcionamento do mercado e suas condições de trabalho, o que, em várias instâncias, determina as possibilidades e limites de sua intervenção.

Os estudos acerca das condições de trabalho do psicólogo no Brasil têm apontado para um quadro de relativa penúria (Bastos, 1990; CFP, 2001; Heloani, Macêdo \& Cassiolato, 2010; Pasquali, 1988). A isso se soma o fato de que os trabalhadores do campo das políticas sociais no Brasil têm sido historicamente desfavorecidos, com políticas de descaso e má remuneração (Chahad, 2003) e, no caso da Psicologia, "este impacto é sem dúvida maior, quando se trabalha nas áreas sociais, normalmente no serviço público que tradicionalmente adota uma política de remunerar indignamente seus servidores" (Bastos, 1990, p. 38). Diante disso, pesquisaram-se as formas e quantidades de inserção remunerada, indicadores de condições de trabalho, como vistos na Figura 2.

A Figura 2 apresenta os dados relativos à inserção profissional, especificamente, a quantidade de locais de trabalho nos quais tem atividade remunerada.

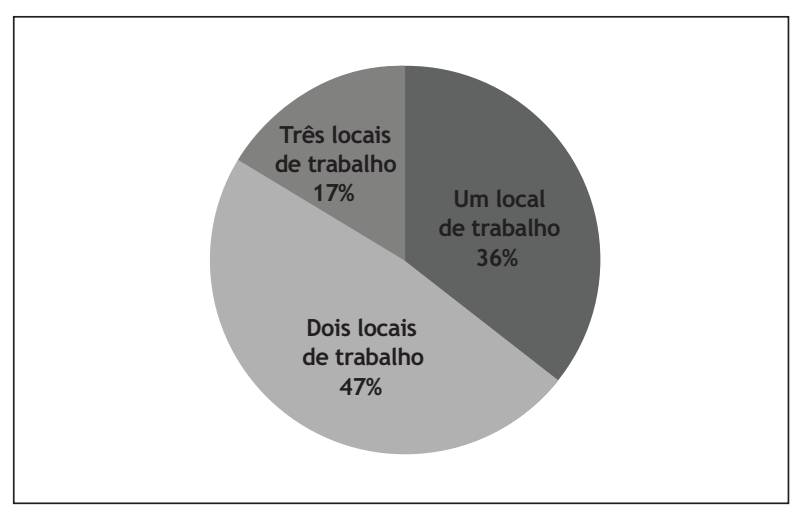

Figura 2 - Quantidade de inserções profissionais dos psicólogos no campo das políiticas sociais com atividade remunerada

Fonte: Dados da pesquisa. 
0 fato de o profissional de Psicologia ter mais de uma inserção no mercado profissional pode ser interpretado de duas formas. Por um lado, podemos perceber que existe campo de trabalho para a Psicologia. 0 campo ainda está aberto e absorve muitos profissionais. Por outro, o fato de o profissional ter que se inserir em mais de um local é comumente associado a um processo de precarização. Primeiro, porque tem de trabalhar mais para sobreviver; segundo, o fato de ter mais de uma inserção dificulta ou impede a dedicação à qualificação e ao investimento pessoal na área, mantendo, assim, uma prática mais estagnada. A precarização, além disso, atinge não só a questão salarial, mas ao funcionário é dificultado tempo livre para outras esferas da vida, como lazer, família, religião, ou mesmo qualificação profissional, fazendo de seu tempo total de trabalho um expediente de reprodução de sua força. Esses dados podem ser corroborados ao confrontar com a carga horária de trabalho e rendimentos, apresentados a seguir.

$\mathrm{Na}$ análise de rendimentos, constatou-se uma baixa remuneração, outro aspecto da precarização dos psicólogos. 0 estudo mostrou que 50,9\% dos profissionais que trabalham nas políticas sociais ganham até quatro salários mínimos (SM), e, cumulativamente, $75,4 \%$ até seis SM. Para se ter uma ideia do quadro apresentado, o psicólogo nordestino, na década de 1990, ganhava, uma média de sete SM (Bastos, 1990). Segundo dados mais atuais (Heloani, Macedo \& Cassiolato, 2010) mais da metade $(60,8 \%)$ dos psicólogos brasileiros possuem um rendimento de no máximo nove SM. Segundo os dados do IBGE (2006), o rendimento médio dos profissionais de nível superior (acima dos 12 anos de estudo) no Rio Grande do Norte era de 13,8 SM, o que coloca os profissionais de Psicologia em piores condições de trabalho.

Além do mais, devemos ainda ressaltar que essa média salarial é da soma dos rendimentos. Ou seja, considerando que $65 \%$ dos profissionais que atuam com políticas sociais o fazem em mais de um local de trabalho, a situação é ainda mais grave. Se tomarmos o rendimento isolado, por local de trabalho, temos uma média de um a dois SM. Isoladamente, os locais que melhor remuneram são os vinculados ao setor de saúde pública e instituições hospitalares. Os que trabalham em ONG e maciçamente os que trabalham no campo da assistência social têm um rendimento inferior. Esses dados indicam que o profissional necessita ter mais de uma inserção profissional para compor um rendimento conjunto satisfatório, atestando a precariedade do mercado de trabalho nesse setor (Bastos \& Gomide, 1989).

Ao estudar a vinculação socioeconômica, observamos que esses profissionais provêm de estratos considerados entre as "classes média e alta". Como eles possuem um rendimento baixo, investigamos o quanto de seus salários corresponde ao salário da família. 0 resultado é que poucos psicólogos são "chefes-de-família", ou seja, as rendas são as principais, pois $67,4 \%$ não chegam a contribuir com mais de $50 \%$ da renda familiar. Esse caráter de salário complementar, adicionado ao fato de que $85 \%$ dos entrevistados não possuem qualquer tipo de benefício adicional ao seu salário, agrava o quadro de precarização da categoria. Todos esses dados estão resumidos no Quadro 1:

\section{Quadro 1 - Quadro síntese dos dados mais relevantes acerca da remuneração mensal dos psicólogos estudados}

\begin{tabular}{|c|c|}
\hline Aspectos analisados & Resultados relevantes \\
\hline \multirow[t]{2}{*}{ Remuneração mensal (RM) } & $\begin{array}{l}\text { - 50,9\% - quatro salários } \\
\text { mínimos (SM). }\end{array}$ \\
\hline & - $75,4 \%$ - até seis SM. \\
\hline \multirow[t]{2}{*}{$\begin{array}{l}\text { Relação entre RM e situação } \\
\text { no mercado de trabalho }\end{array}$} & $\begin{array}{l}\cdot 69,2 \% \text { - inseridos em um } \\
\text { local de trabalho ganham de } \\
\text { um a dois SM. }\end{array}$ \\
\hline & $\begin{array}{l}\text { 60\% - inseridos em mais de } \\
\text { um local de trabalho ganham } \\
\text { até seis SM. }\end{array}$ \\
\hline \multirow[t]{4}{*}{$\begin{array}{l}\text { Relação entre RM e locais de } \\
\text { trabalho em política social }\end{array}$} & $\begin{array}{l}\text { - Assistência social - 81\% de } \\
\text { um a dois SM. }\end{array}$ \\
\hline & - ONG $-61,5 \%$ de um a dois SM \\
\hline & $\begin{array}{l}\text { - Instituiçãa de saúde coletiva - } \\
43,9 \% \text { de três a quatro SM. }\end{array}$ \\
\hline & $\begin{array}{l}\text { - Instituição hospitalar - } \\
\text { 35,3\% de três a quatro SM e } \\
\text { 29,4\% de cinco a seis SM. }\end{array}$ \\
\hline \multirow[t]{2}{*}{ Participação na renda familiar } & - $38,1 \%$ - contribuem em $30 \%$. \\
\hline & $\begin{array}{l}\text { - } 67,4 \% \text { - contribuem no } \\
\text { máximo em } 50 \% .\end{array}$ \\
\hline
\end{tabular}

Fonte: Dados da pesquisa.

Com relação à carga horária, confirma-se a expectativa criada pelo fato de a maior parte dos profissionais ter mais de uma inserção, de uma jornada longa de trabalho. De fato, mais de $65 \%$ dos profissionais 
trabalham mais de trinta horas, e um número expressivo $(37,2 \%)$, mais de quarenta horas. A média de trabalho desses profissionais é de quarenta e uma horas semanais. Confrontando os dados presentes com os do estudo de 1988, a carga média de trabalho aumentou e a remuneração, proporcionalmente, diminuiu.

Foram pesquisadas também outras informações complementares à análise das condições de trabalho. Em termos de carreira e permanência no emprego, temos duas situações distintas. No campo da saúde pública, a maior parte dos profissionais atua mais de 10 anos, contratados com carteira assinada (celetistas) tendo ingressado por concurso público. Já os trabalhadores das ONGs e do setor da assistência social estão há pouco tempo, muitos não possuem carteira assinada e não são concursados. Isso denota condições de trabalho adversas nesse segmento, indicadores de possível rotatividade e instabilidade no emprego. 0 "terceiro setor" tem o agravante de possuir o maior índice de trabalhadores voluntários. As informações sobre aspectos das condições de trabalho encontram-se no Quadro 2:

\section{Quadro 2 - Quadro síntese dos resultados mais relevantes acerca das condições de trabalho dos psicólogos estudados}

\begin{tabular}{ll}
\hline Aspectos analisados & Resultados relevantes \\
\hline Horas de trabalho & $\bullet 65 \%$ trabalham 30h; \\
& $\bullet 37,2 \%$ trabalham mais de $40 \mathrm{~h} ;$ \\
& $\bullet$ Média de 41h semanais \\
Tempo no local de & $\bullet 41,3 \%$ estão há menos de 3 \\
trabalho & anos, desses, 63,2\% são da \\
& $\bullet 38,8 \%$ estão há mais de 10 \\
& anos, desses, 28,6\% são de \\
& Instituições de Saúde Coletiva. \\
& $\bullet 45,7 \%$ - carteira assinada \\
Regime de trabalho & $\bullet 34,1 \%$ - prestação de serviços \\
Forma de ingresso & $\bullet 41,9 \%$ - convite/indicação \\
& $\bullet 36,4 \%$ - concurso público \\
\hline
\end{tabular}

Fonte: Dados da pesquisa.

Outro dado interessante é o fato de que atualmente esses trabalhadores estão atuando em Psicologia, ou seja, são contratados como psicólogos e não em desvios de função. Esses dados contrastam com os de 1988, época na qual havia um número expressivo de desvios e muitas instituições contratavam o psicólogo para outras funções (Pasquali, 1988). Isso traduz num maior reconhecimento social do trabalho desse profissional, o que implica melhores condições de trabalho.

Em síntese, os resultados sobre a inserção profissional do psicólogo no campo das políticas sociais e sua condição de trabalho não configuram um cenário muito animador. Estudos anteriores já apontavam que o psicólogo no Brasil, de forma geral, é uma categoria precarizada, mesmo entre aqueles que escolheram trabalhar como autônomos. Acrescente a esse cenário a já discussão das baixas condições de trabalho atribuídas aos profissionais da área social. Os profissionais-alvo deste estudo não fugiram ao cenário exposto. Os dados indicam um psicólogo que precisa inserir-se em mais de um local de trabalho, na sua maioria de natureza extremamente diversa. A renda dos profissionais que trabalham no campo das políticas sociais é mais baixa que a média da categoria de psicólogos atualmente, e até de 20 anos atrás. Mesmo estando em situação familiar relativamente confortável, sua renda contribui pouco para sua família. Não possuem benefícios trabalhistas adicionais, o salário é indireto. Trabalham uma média de horas semanal maior do que o resto da categoria, graças, inclusive, à multiplicidade de locais em que se inserem. 0 pouco tempo restante é destinado à formação complementar, possivelmente para melhorar sua inserção, ou garantir-se no mercado. Esses postos de trabalho oferecem contratos temporários na mesma proporção que com carteira assinada. Uma boa parte desses profissionais, sobretudo os ligados à Assistência Social, possuem vínculos trabalhistas instáveis e, pela natureza de seus contratos de trabalho e o tempo que estão inseridos, há provavelmente um alto índice de rotatividade nos seus locais. Os profissionais estudados, enfim, aparentam estar em um cenário desolador, em uma profissão que já não apresentava condições favoráveis.

\section{A ałuaccão profissional do psicólogo no campo das políticas sociais}

As análises da atuação profissional do psicólogo no país indicam uma profissão heterogênea no que refere às áreas e aos locais de atuação, de técnicas e de aportes teóricos (Carvalho, 1988; CFP, 2001, 2004; Gondim, Bastos \& Peixoto, 2010).

A análise que se segue foi conduzida para verificar se esse quadro de heterogeneidade também é encontrado entre os profissionais que atuam no campo das políticas sociais. 


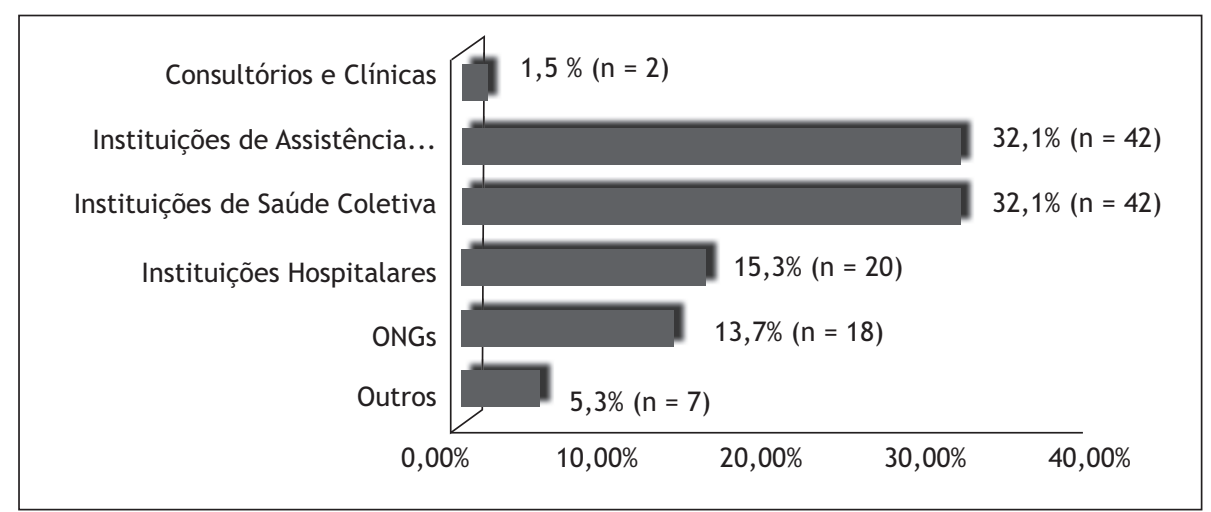

Figura 3 - Distribuição dos psicólogos no campo das políticas sociais por local de trabalho

Fonte: Dados da pesquisa.

0 primeiro destaque diz respeito à distribuição geral dos profissionais pelos diversos campos das políticas sociais. Como podemos observar na Figura 3, os campos da saúde e da assistência social aparecem em igual proporção (32\%), a despeito da inserção mais expressiva no último ser mais recente. Contudo, se tomarmos em conjunto as Instituições Hospitalares com as de Saúde Coletiva, o campo da saúde pública seria aquele que concentraria a maior parte dos psicólogos que atuam com políticas sociais $(47,4 \%)$.

Um segundo destaque diz respeito à presença de psicólogos atuando em ONGs. Considerando o fato de que, há alguns anos, essa inserção era insignificante, os $13 \%$ de profissionais em ONGs não deixa de ser um fato digno de registro.

0 que chama atenção nesses dados é o rápido crescimento do setor de assistência social. A inserção nesse campo, antes da implementação do Sistema Único de Assistência Social (SUAS), era quase inexistente, sendo restrita a alguns psicólogos que trabalhavam em projetos específicos dos municípios. E agora já possui uma inserção que rivaliza com o campo da saúde, que já possui pelo menos duas décadas de consolidação de seu trabalho (Oliveira et al., 2004).

Tendo em vista a informação de que $42 \%$ dos profissionais informaram mais de uma inserção profissional (Figura 2), resta a questão referente a quais outras inserções são essas. Os dados indicam que a combinação mais presente é a clínica. Dos locais que aparecem sem combinações, o mais recorrente são as instituições de assistência social. Nossa hipótese é que esses locais concentram grande quantidade de recém-formados que se submetem a condições precárias de trabalho (instáveis, contratos temporários, baixa remuneração), enquanto aguardam oportunidades para migrar para outros campos de atuação.

Outro aspecto da profissão analisado foi a área da Psicologia na qual o profissional atua. A despeito de ser um tema difícil de definir na literatura, a noção de área tem sido bastante estudada (Mello, 1975; Bastos, 1988; Yamamoto, 1988; Gondim, Bastos \& Peixoto, 2010). Mesmo controverso, o tema torna-se importante estudar, pois nos remete a pistas da identidade do psicólogo. A área mais citada foi a Social, com $31,3 \%$ das respostas válidas, seguidas pela Clínica, 25,2\% e Saúde, com 12,2\%. Numa análise preliminar, há certo otimismo na resposta graças a prevalência da área Social (o que não só é esperado, como defendido). No entanto, a presença marcante da Clínica ainda permanece $(25,2 \%)$, sobretudo se levarmos em consideração que todos os locais estudados são situados no campo das políticas sociais. A presença da área Social também deve ser investigada com maior cuidado, pois o profissional pode ter consciência de que atua na área social, mas sua prática profissional ser completamente diferente. Para dirimir essas dúvidas, realizamos um cruzamento da área com local de atuação. Observamos, então, que a área Clínica aparece mais associada aos locais de Saúde Coletiva. A relação entre os psicólogos que trabalham nas Unidades Básicas de Saúde (UBS) e determinadas práticas profissionais já havia sido discutida por outros autores (Oliveira et al., 2004). Interessante notar que a área da Saúde aparece associada em igual proporção tanto às Instituições de Saúde Coletiva quanto às Instituições de Assistência Social. A área Clínica é também preponderante nas ONGs, reforçando um 
modelo tradicional e historicamente constituído de atuação. A área Social aparece, por sua vez, mais vinculada às Instituições de Assistência Social. De fato, independente das atividades desenvolvidas, o psicólogo parece ter a noção de que esse local de trabalho específico encontra-se na área da Psicologia denominada Social. Dados complementares são necessários para avaliar se essa identidade é construída (e aceita) pelos profissionais ou, simplesmente, imposta pelas políticas recém-inauguradas.

Em seguida, questionamos os profissionais acerca do seu vínculo teórico-metodológico. Na Tabela 1, apresentamos a disposição das respostas:

\section{Tabela 1 - Distribuição dos psicólogos no campo das políticas sociais por abordagem teórico-metodológica}

\begin{tabular}{lcc}
\hline Abordagem teórico-metodológica & $\mathbf{n}$ & $\mathbf{\%}$ \\
\hline Psicodinâmica & 44 & 33,6 \\
Corporais & 5 & 3,8 \\
\hline $\begin{array}{l}\text { Fenomenológica-existencial/ } \\
\text { Humanista }\end{array}$ & 19 & 14,5 \\
Sócio-histórica/Crítica & 11 & 8,4 \\
Cognitivo-comportamental & 5 & 3,8 \\
Eclética & 7 & 5,3 \\
Outras & 7 & 5,3 \\
\hline Não se aplica & 34 & 26,0 \\
\hline
\end{tabular}

Fonte: Dados da pesquisa.

Repetindo um padrão nacional e regional da Psicologia (Bastos \& Gomide, 1989; Gondim, Bastos \& Peixoto, 2010; Yamamoto et al., 2003) as teorias psicodinâmicas foram as mais citadas (33,6\%). Em seguida, temos a categoria Não respondeu/Não se aplica (26\%) e as Fenomenológicas existenciais-humanistas $(14,5 \%)$. Vale destacar aqui que teorias sócio-históricas ou críticas ${ }^{1}$ apareceram em apenas $8,4 \%$ dos casos. A presença marcante de respostas inadequadas (ou em branco) não foi de todo estranha. Estudos anteriores registram a dificuldade de os psicólogos descreverem uma abordagem teórico-metodológica, confundindo muitas vezes com técnicas ou procedimentos, com respostas como "dinâmica de grupo". Além disso, os psicólogos que trabalham nesses novos locais não têm encontrado na ciência psicológica abordagens características próprias e bem difundidas na área, como lembra Yamamoto (2007) e Yamamoto et al. (2001, 2003). Esses modelos de abordagens por escolas ou sistemas estão historicamente relacionados à área clínica.

Mais uma vez, visando a entender melhor o fenômeno, realizamos um cruzamento das abordagens citadas com os locais de trabalho. As abordagens psicodinâmicas estão mais relacionadas ao campo da saúde coletiva, dados já apresentados pela literatura no Rio Grande do Norte (Oliveira et al., 2004). Já as abordagens sócio-históricas/críticas foram mais citadas pelos profissionais do campo da assistência social, o que poderia ser um fato promissor para o campo. No entanto, percebemos também que as Instituições de Assistência Social estão relacionadas a quase todas as abordagens, além de um alto número de respostas inadequadas. Esse caráter difuso está presente também nas ONGs, corroborando a confusão que o campo causa nos profissionais.

Por fim, realizamos um levantamento das atividades desenvolvidas pelos profissionais de Psicologia que estão inseridos no campo das políticas sociais. Em uma análise preliminar, listamos a frequência das atividades desenvolvidas pelos psicólogos no campo $^{2}$. Abaixo, na Tabela 2, apresentamos as cinco atividades mais realizadas:

Tabela 2 - Cinco atividades mais realizadas pelos psicólogos inseridos nas políticas sociais

\begin{tabular}{lll}
\hline Atividade realizada & $\mathbf{n}$ & $\mathbf{\%}$ \\
\hline $\begin{array}{l}\text { Psicoterapia individual (adulto, criança } \\
\text { e adolescente) }\end{array}$ & 52 & 39,7 \\
$\begin{array}{l}\text { Orientação de pais } \\
\text { Atendimento a crianças com distúrbios } \\
\text { de aprendizagem }\end{array}$ & 34 & 36,6 \\
$\begin{array}{l}\text { Pareceres e laudos psicológicos } \\
\text { Participação em equipes técnicas }\end{array}$ & 29 & 26,0 \\
\hline
\end{tabular}

Fonte: Dados da pesquisa.

\footnotetext{
1 Foram consideradas aqui abordagens com interfaces sociológicas, políticas e/ou filosóficas, tais como as teorias marxistas, as construtivistas ou mesmos as irracionalistas.

${ }^{2}$ No questionário aplicado apresentávamos uma lista prévia de 47 atividades, em que o psicólogo deveria marcar as cinco mais realizadas em cada local de trabalho.
} 
A atividade mais desenvolvida foi a Psicoterapia Individual $(39,7 \%)$, seguida da Orientação de pais $(36,6 \%)$ e Atendimento a crianças com distúrbios de aprendizagem (26\%). A presença da Psicoterapia Individual como a atividade mais realizada deve ser visto com cautela, pois estamos falando de locais que lidam com políticas sociais. No estudo em 2001, Yamamoto e colaboradores já haviam sinalizado a presença marcante da psicoterapia em espaços não tradicionais. No estudo citado, a atividade psicoterapia estava relacionada com os locais vinculados à política social na ordem de $73,2 \%$. Num primeiro momento, poderíamos pensar que avançamos na questão, em função da diminuição do valor, se compararmos os dados das duas pesquisas. No entanto, se somarmos todas as modalidades de psicoterapia da nossa atual pesquisa (grupo, casal, familiar e individual) temos o impressionante número de $72,5 \%$. Ou seja, mesmo em locais específicos para atuação em políticas sociais, quase três quartos dos profissionais se valem da prática psicoterápica. As demais atividades fazem parte do rol das atividades clássicas dos profissionais, com exceção a "Participação em equipes técnicas". Essa última especula-se que a presença seja em função do funcionamento das políticas sociais no país (com destaque para SUS e SUAS) cuja forma de operar é eminentemente em equipes multiprofissionais (Yamamoto \& Oliveira, 2010).

$\mathrm{Na}$ Tabela 3, temos o cruzamento das atividades desenvolvidas com os locais de trabalho:

Tabela 3 - Cinco principais atividades desenvolvidas pelos psicólogos no campo das políticas sociais por local de atuação

(Continua)

\begin{tabular}{llcc}
\hline Local & Atividades & n & \% \\
\hline Instituições & Orientação de pais & 24 & 57,1 \\
de Assistência & Orientação a adolescentes & 18 & 42,9 \\
Social & Orientação à gestante & 14 & 33,3 \\
& Orientação sexual & 13 & 31,0 \\
& Dinâmica de grupo & 12 & 28,6 \\
& Psicoterapia individual (adulto, & 24 & 57,1 \\
Instituições de & criança e adolescente) & & \\
Saúde Coletiva & Atendimento a crianças com & 14 & 33,3 \\
& distúrbios de aprendizagem & & \\
& Orientação de pais & 13 & 31,0 \\
& Orientação a grupos na área de & 13 & 31,0 \\
& saúde pública & & \\
& Psicoterapia de grupo & 13 & 31,0 \\
\hline
\end{tabular}

Tabela 3 - Cinco principais atividades desenvolvidas pelos psicólogos no campo das políticas sociais por local de atuaç̃ão

(Conclusão)

\begin{tabular}{llcc}
\hline Local & Atividades & n & \% \\
\hline Instituições & Assistência psicológica a pacientes & 14 & 70,0 \\
Hospitalares & $\begin{array}{l}\text { clínicos e cirúrgicos (cardíacos, } \\
\text { mutilados, terminais etc.) }\end{array}$ & & \\
& $\begin{array}{l}\text { Psicoterapia individual (adulto, } \\
\text { criança e adolescente) }\end{array}$ & 9 & 45,0 \\
& Psicoterapia de grupo & 6 & 30,0 \\
& Pareceres e laudos psicológicos & 5 & 25,0 \\
& $\begin{array}{l}\text { Supervisão de estágios acadê- } \\
\text { micos }\end{array}$ & 4 & 20,0 \\
ONGs & $\begin{array}{l}\text { Psicoterapia individual (adulto, } \\
\text { criança e adolescente) }\end{array}$ & 8 & 44,4 \\
& $\begin{array}{l}\text { Orientação de pais } \\
\text { Atendimento a crianças com } \\
\text { distúrbios de aprendizagem } \\
\text { Cargo administrativo (gerência } \\
\text { ou direção) }\end{array}$ & 7 & 38,9 \\
Intervenção em organizações e & 5 & 27,8 \\
instituições & 22,2 \\
\hline
\end{tabular}

Fonte: Dados da pesquisa.

Constatamos, primeiramente, que com exceção das Instituições de Assistência Social, a Psicoterapia Individual figura como umas das principais atividades em quase todos os locais que trabalham com política social. A despeito de essa prática profissional ser extremamente criticada nos espaços que lidam com política social, esse dado já era apontado na literatura sobre o assunto no Rio Grande do Norte, especificamente no caso dos hospitais e instituições de saúde coletiva (Yamamoto \& Cunha, 1998; Oliveira et al., 2004). No estudo de 2003, Yamamoto et al. já apontavam que os psicólogos das ONGs no Rio Grande do Norte também realizam atividades psicoterápicas individuais (Paiva \& Yamamoto, 2008). As demais atividades citadas nos locais vinculados à área da Saúde (instituições de saúde coletiva e instituições hospitalares) parecem estar de acordo com os dados já coletados na literatura.

Cruzando os dados referentes às atividades com as três áreas da Psicologia mais citadas neste estudo (clínica, saúde e social), verificamos que a atividade psicoterápica é quase que integralmente associada a área clínica. Esse dado é importante pois a área clínica é associada com todos os locais de trabalho citados. Ou seja, a atividade preponderante no campo 
das políticas sociais é a Psicoterapia. Na área social, um dado promissor: as atividades "Dinâmica de Grupo", "Planejamento e execução de projetos" e "Desenvolvimento de grupos e equipes" foram citadas por $29,3 \%, 26,8 \%$ e $26,8 \%$, respectivamente. Esse dado poderia representar práticas mais alinhadas com as novas demandas impostas pelas comunidades nas quais o psicólogo se insere, que não aparecem na literatura de forma tão presente (CFP, 2001, 2004; Yamamoto et al., 2001, 2003). No entanto temos que avaliar se o aparecimento dessas práticas deve-se mais às imposições das políticas do que a inovações teórico-técnicas da própria categoria. Em suma, as associações de determinadas áreas, locais e atividades estão em consonância com nossa análise.

Resumindo, o que nossos dados sobre a atuação do profissional no campo das políticas sociais apontaram? Esses psicólogos tiveram uma formação clínica, baseados em modelos de estágios profissionalizantes nessa área. Poucos optam, seja por "vocação", seja pela baixa oferta, realizar Formação Complementar em áreas que produzam ou problematizem essas práticas nos espaços onde estão inseridos. As abordagens teórico-metodológicas utilizadas são as das escolas tradicionais que, historicamente no Brasil, alinham-se politicamente a trabalhos extremamente conservadores, com forte herança das práticas psicoterápicas, ideologicamente vinculadas com a burguesia, exemplificado pela presença sempre constante da psicanálise (Coimbra, 1995). Percebem sua atuação principalmente no contexto das áreas Clínica, de Saúde ou Social. As duas primeiras apresentam as mesmas características, e não diferem em nada das concepções tradicionais já citadas. Já a identificação com a área Social relaciona-se com os locais ligados ao campo da Assistência Social, e com algumas práticas potencialmente inovadoras, mas que também poderiam "esconder", em sua essência, os mesmos determinantes liberais de outrora. De forma geral, não há muita novidade nas atividades desenvolvidas nesse campo. Se fizermos uma retrospectiva histórica, tendo como ponto de análise os dados apresentados, parece que caminhamos mais na direção de consolidar práticas conservadoras do que de apresentar inovações efetivas. A impressão final é de que essa forma de atuação não contempla as novas demandas apresentadas ao profissional de Psicologia que se insere no campo das políticas sociais.

\section{0 que resta aos psicólogos no campo das políticas sociais na atualidade?}

Ainda que atualmente o Conselho Federal de Psicologia assuma o discurso do compromisso social, e venha tentando divulgar essa orientação política (Bock, 1999, 2003; Lopes, 2005), a noção de atuação comprometida ainda é muito difusa e heterogênea. E mesmo com o aumento significativo desse tipo de discurso, ele ainda está longe de ser hegemônico na categoria. No entanto os dados apresentados pela pesquisa são inegáveis, a política social não é uma excrescência dentro da Psicologia brasileira. Se entendermos que a entrada dos psicólogos nesse campo já vinha sendo sinalizada pelas pesquisas, e que sua expansão num curto espaço de tempo tem sido atrelada às mudanças nas formas de elaboração e execução das políticas sociais no país, temos um dado relevante, que essa realidade descrita nesse escrito deve ser a realidade da categoria no país. A despeito de uma ou outra discrepância entre a Psicologia norteriograndense e a brasileira, as semelhanças parecem recorrentes.

A pesquisa tentou responder algumas questões importantes: como o psicólogo está inserido nesse campo e que respostas tem dado nesse "novo" segmento. Descobrir e analisar essas questões pode aproximar a categoria dos objetivos políticos defendidos há tanto tempo, e hoje em dia, de forma cada vez mais frequente. Como visto neste estudo, os modelos clássicos (médico-clínico) continuam recorrentes. E, historicamente, o modelo médico "clínico", acatado na maior parte das instâncias formadoras, acaba se alinhando como uma perspectiva individualizante e acrítica, o que enviesaria as possibilidades de trabalho com uma demanda diferente daquelas apresentadas durante a formação.

A situação torna-se um pouco pior, ainda nessa linha de raciocínio, pois esses profissionais não tiveram muita experiência profissional que os habilite a confrontar o modelo aprendido no curso, já que são em sua maioria, recém-formados. Essa hipótese é fortalecida quando confrontamos com as atividades desenvolvidas no campo, apesar de certa compreensão contemporânea que não há novos modelos consolidados que se coloquem como alternativa de atuação para esses profissionais. E a formação continuada desses psicólogos, como discutido na caracterização desses profissionais, é feita na área clínica, sobretudo em especializações 
profissionalizantes, reforçando assim modelos de intervenção tradicional.

É preciso perceber, no entanto, que a atuação do psicólogo no campo das políticas sociais não está desvinculada das macroquestões, incluindo suas condições reais de reprodução material. A forma e o desenvolvimento das políticas cria certas condições de trabalho que não só influenciam, mas em muitos casos determinam, aspectos ligados a intervenção desse profissional. Essa determinação das políticas está presente desde a formulação de documentos oficiais, que criam parâmetros de trabalho (vide os referenciais atuais do SUS e do SUAS), até atrativos para o campo como estabilidade, remuneração digna, jornada de trabalho justa, dando a esse profissional a não necessidade de sofrer as próprias sequelas que tenta combater.

Com base na condução atual das políticas sociais $^{3}$, e assumindo que essa condição irá se manter por algum tempo, podemos fazer algumas inferências. Podemos esperar para os psicólogos no campo das políticas sociais que a situação atual se manterá. Ou seja, uma situação de extrema precariedade, como atestado por este estudo, mas em expansão. Se houver uma continuidade da lógica de articulação das políticas sociais como feitos pelo governo atual, temos um constante investimento, que ainda sendo feito de forma desqualificada, continua aumentando as contratações do psicólogo no setor público. Uma proteção social que, em teoria, é avançada e contemporânea, mas que, na execução, sofre de falta de recursos e submete os profissionais do setor a uma inserção precarizada (Marques \& Mendes, 2007).

Com base em alguns desses dados e análises subsequentes, podemos perceber um quadro que de forma geral parece desanimador. 0 campo da política social não parece atrativo, em termos de mercado de trabalho, para o psicólogo. Mas ele pode ser instado a intensificar sua inserção no campo por conta da própria retração do mercado de trabalho, consequência da crise, e ocupando vários espaços, simultaneamente. Esse profissional passa, então, a não investir em estudar e entender o novo campo, não faz formação complementar nessa direção, além da própria pulverização de esforços cotidianos, por conta da multiplicidade de locais inseridos.

A bem da verdade, a situação parece estar complicando, pois a entrada maciça no campo (lembrando nosso número de $41 \%$ ) vai demandar novas posturas profissionais, éticas inclusive, e maior eficácia no trabalho com esses novos grupos sociais, coisas que aparentemente os psicólogos não têm e não estão desenvolvendo.

A partir da análise histórica da inserção dos psicólogos no campo das políticas sociais, percebemos que muitos avanços esperados ainda não estão acontecendo. Para ilustrar a questão, analisemos o caso dos psicólogos inseridos nas instituições ligadas às políticas públicas de Saúde, que durante esse tempo acabou consolidando suas práticas de 20 anos atrás, e, ao invés de inovar, difundiram ainda mais os modelos tradicionais, mostrando que é possível lidar com várias das sequelas da "Questão Social" usando as teorias e técnicas tradicionais (Yamamoto \& Oliveira, 2010). O receio é que o campo da assistência social possa estar "reproduzindo" esse movimento da saúde coletiva. É difícil argumentar que o campo da assistência social pode "revolucionar" suas práticas apenas pelo contato com novos atores, ou novos problemas. 0 que temos, finalmente, é um cenário único, de reprodução de valores liberais, de corroborações de padrões clássicos, na propagação e difusão de uma prática apolítica e acrítica. 0 discurso permite, inclusive, a propagação do "Terceiro Setor" como estratégia de combate às sequelas da "Questão Social", que vem também crescendo, com os mesmos vícios e modelos de seus lugares "cossemelhantes".

Não intencionamos entrar no mérito das impossibilidades de mudança estrutural da sociedade pela atividade do psicólogo, ou dos limites de sua ação $0^{4}$. Estamos refletindo sobre a possibilidade de $o$ psicólogo perceber seus limites e possibilidades de uma ação comprometida nos marcos do sistema capitalista, e poder pensar e elaborar modelos e práticas que pareçam, mesmo que remotamente, com qualquer outra possibilidade de ação.

Reforçamos a importância de estudos dessa natureza que podem levar à categoria dados que

\footnotetext{
3 Esse texto foi escrito no período imediatamente posterior as eleições presidenciais, que podem, ou não, alterar os rumos das políticas. Acredita-se, pela característica político-partidária da nova presidenta, que haverá uma continuidade na forma de condução dessa questão.

4 Remetemos o leitor para Yamamoto $(1987,2007)$, Yamamoto \& Oliveira (2010) e Figueiredo (1989).
} 
permitam realizar mais análises críticas de sua condição, objetivando formular transformações orientadas, ou seja, políticas, para lidar com essa situação. Entendemos que um dos grandes méritos dessa pesquisa foi demonstrar que não estamos mais lidando com uma "área" da Psicologia, ou um segmento "emergente": a política social é lugar comum agora; é a Psicologia em mais contato com o mundo real, material. A despeito de parecer ineditismo, esta pesquisa pode servir como um (re)alerta, de algo que já está em movimento a algum tempo.

A situação social que se avilta para nossos trabalhadores poderia ser uma força motriz de reflexão acerca do capitalismo na contemporaneidade e pensar possíveis "transformações". E pode ser que a Psicologia possa contribuir com algo. Regina Campos, em seu texto de 1990, "a função social do psicólogo revisitada”, já lembrava que, na própria história da Psicologia, existem exemplos de ações que tenham como embasamento alinhamentos políticos de "contradominação". Articular os elementos atuais em uma direção que Yamamoto (2007) chamou de ampliar os limites da dimensão política de sua ação profissional.

\section{Referências}

Bastos, A. V. B. (1988). Áreas de atuação: Em questão o nosso modelo profissional. In Conselho Federal de Psicologia (Org.). Quem é o psicólogo brasileiro (pp. 163-193). São Paulo: EDICON.

Bastos, A. V. B. (1990). Mercado de trabalho: Uma velha questão e novos dados. Psicologia: Ciência e Profissão, 10(2), 28-39.

Bastos, A. V. B., \& Gomide, P. I. C. (1989). O psicólogo brasileiro: Sua atuação e formação profissional. Psicologia: Ciência e Profissão, 9(2), 5-15.

Bastos, A. V. B., Gondim, S. M. G., \& Rodrigues, A. C. A. (2010). Uma categoria profissional em expansão: Quantos somos e onde estamos? In A. V. Bastos \& S. M. Gondim (Org.). 0 trabalho do psicólogo no Brasil (pp. 32-44). Porto Alegre: Artmed.

Bock, A. M. B. (1999). Aventuras do Barão de Munchausen na Psicologia. São Paulo: EDUC; Cortez.
Bock, A. M. B. (2003). Psicologia e sua ideologia: 40 anos de compromisso com as elites. In A. M. Bock (Org.). Psicologia e o compromisso social (pp. 15-28). São Paulo: Cortez.

Botomé, S. P. (1979). A quem nós, psicólogos, servimos de fato? Psicologia, 5(1), 1-16.

Campos, R. H. F. (1983). A função social do psicólogo. Educação \& Sociedade, 16, 74-84.

Campos, R. H. F. (1990). A função social do psicólogo revisitada. Psicologia e Sociedade, 5(8), 17-21.

Carvalho, A. M. A. (1988). Atuação psicológica: Uma análise das atividades desempenhadas pelos psicólogos. In Conselho Federal de Psicologia (Org.). Quem é o psicólogo brasileiro (pp. 217-235). São Paulo: EDICON.

Chahad, J. P. Z. (2003). Tendências recentes no mercado de trabalho: Pesquisa de emprego e desemprego. São Paulo em Perspectiva, 17(3/4), 205-217.

Coimbra, C. M. B. (1995). Guardiães da ordem: Uma viagem pelas práticas Psi no Brasil do Milagre. Rio de Janeiro: Oficina do Autor.

Conselho Federal de Psicologia. (Org.). (2001). Pesquisa feita junto aos associados do Conselho Federal de Psicologia: Relatório final. Recuperado em 27 jul. 2002, em http://www.pol.org.br/arquivos_pdf/relatório_who.doc

Conselho Federal de Psicologia. (Org.). (2004). Pesquisa de opinião com psicólogos inscritos no Conselho Federal de Psicologia: Relatório final. Recuperado em 15 mar. 2006, em http://www.pol.org.br/publicacoes/pdf/Pesquisa_IBOPE.pdf

Dimenstein, M. (1998). O psicólogo no serviço público de saúde: Impasses na formação e atuação profissionais. Estudos de Psicologia (Natal), 3(1), 53-81.

Figueiredo, M. A. C. (1989). 0 trabalho alienado \& o psicólogo do trabalho: Algumas questões sobre o papel do psicólogo no controle da produção capitalista. São Paulo: EDICON.

Gondim, S. M. G., Bastos, A. V. B., \& Peixoto, L. S. A. (2010). Áreas de atuação, atividades e abordagens teóricas do psicólogo brasileiro. In A. V. Bastos \& S. M. Gondim (Org.). 0 trabalho do psicólogo no Brasil (pp. 174199). Porto Alegre: Artmed. 
Heloani, J. R. M., Macedo, K. B., \& Cassiolato, R. (2010). 0 exercício da profissão: características gerais da inserção profissional do psicólogo. In A. V. Bastos \& S. M. Gondim (Org.). 0 trabalho do psicólogo no Brasil (pp. 107-130). Porto Alegre: Artmed.

Instituto Brasileiro de Geografia e Estatística - IBGE. (2006). Síntese dos indicadores sociais - estudos \& pesquisas: Informação demográfica e socioeconômica número 19. Rio de Janeiro: IBGE.

Lopes, A. A. (2005). 0 compromisso social dos psicólogos brasileiros evidenciado nas publicações da revista Psicologia Ciência e Profissão. Dissertação de Mestrado, Universidade Federal de Santa Catarina, Florianópolis.

Macedo, K. B., Heloani, J. R. M., \& Cassiolato, R. (2010). O psicólogo como trabalhador assalariado: Setores de inserção, locais, atividades e condições. In A. V. Bastos \& S. M. Gondim (Org.). 0 trabalho do psicólogo no Brasil (pp. 131-150). Porto Alegre: Artmed.

Marques, R. M., \& Mendes, A. (2007). Servindo a dois senhores: As políticas sociais no governo Lula. Revista Katalysis, 10(1), 15-23.

Mello, S. L. (1975). Psicologia e profissão em São Paulo. São Paulo: Ática.

Oliveira, I. F. et al. (2004). O psicólogo nas Unidades Básicas de Saúde: Formação acadêmica e prática profissional. Interações, 9(17), 71-89.

Paiva, I. L., \& Yamamoto, O. H. (2008). Os novos quixotes da Psicologia e a prática social no "terceiro setor". Psicologia Política, 8(16), 231-250.

Pasquali, L. (1988). Condições de trabalho do psicólogo. In Conselho Federal de Psicologia (Org.). Quem é o psicólogo brasileiro (pp. 149-162). São Paulo: EDICON.
Rosas, P., Rosas, A., \& Xavier, I. B. (1988). Quantos e quem somos. In Conselho Federal de Psicologia. (Org.). Quem é o psicólogo brasileiro (pp. 32-48). São Paulo: EDICON.

Silva, C. G. A. (2004). Psicologia e compromisso social: Intenção e realidade. Dissertação de Mestrado, Universidade de São Paulo, São Paulo.

Yamamoto, O. H. (1987). A crise e as alternativas da Psicologia. São Paulo: EDICON.

Yamamoto, O. H. (1988). Apontamentos para um estudo da Psicologia em Natal: Áreas de atuação e seus determinantes. Revista de Psicologia, 6(1), 3-13.

Yamamoto, O. H. (2003). Questão social e políticas públicas: Revendo o compromisso da Psicologia. In. A. M. B. Bock (Org.). Psicologia e o compromisso social (pp. 37-54). São Paulo: Cortez.

Yamamoto, O. H. (2007). Políticas sociais, "terceiro setor" e "compromisso social": Perspectivas e limites do trabalho do psicólogo. Psicologia e Sociedade, 19(1), 30-37.

Yamamoto, O. H., \& Cunha, I. M. F. F. O. (1998). 0 psicólogo em hospitais de Natal: Uma caracterização preliminar. Psicologia: Reflexão e Crítica, 11(2), 345-362.

Yamamoto, O. H., Dantas, C. M. B., Costa, A. L. F., Alverga, A. R., Seixas, P. S., \& Oliveira, I. F. (2003). A profissão de psicólogo no Rio Grande do Norte. Interação, 7(2), 23-30.

Yamamoto, O. H., Silva, F. L., Câmara, R. A., \& Dantas, C. M. B. (2001). Espaços, práticas: 0 que há de novo na Psicologia do Rio Grande do Norte? Psicologia em Estudo, 6(1), 65-72.

Yamamoto, O. H., \& Oliveira, I. F. (2010). Política social e Psicologia: Uma trajetória de 25 anos. Psicologia: Teoria e Pesquisa, 26(1), 9-24. 